\title{
Benchmarking in the Supply Chain Using Data Envelopment Analysis
}

\author{
Necmi K. Avkiran1, Morteza Shafiee², Hilda Saleh³, Mahdi Ghaderi4 \\ ${ }^{1}$ UQ Business School, the University of Queensland, St Lucia, Australia \\ ${ }^{2}$ Industrial Management, Economic and Management Faculty, Shiraz Branch, Islamic Azad University, \\ Shiraz, Iran \\ ${ }^{3}$ Department of Mathematics, Faculty of Science, Central Tehran Branch, Islamic Azad University, \\ Tehran, Iran \\ ${ }^{4}$ Department of Industrial Management, Economic and Management Faculty, Shiraz Branch, Islamic Azad University, \\ Shiraz, Iran \\ Email:n.avkiran@business.uq.edu.au,ma.shafiee277@gmail.com, hilda_saleh@yahoo.com,m.ghaderi87@gmail.com
}

How to cite this paper: Avkiran, N.K., Shafiee, M., Saleh, H. and Ghaderi, M. (2018) Benchmarking in the Supply Chain Using Data Envelopment Analysis. Theoretical Economics Letters, 8, 2987-3015. https://doi.org/10.4236/tel.2018.814186

Received: August 2, 2018

Accepted: October 21, 2018

Published: October 24, 2018

Copyright $\odot 2018$ by authors and Scientific Research Publishing Inc. This work is licensed under the Creative Commons Attribution International License (CC BY 4.0).

http://creativecommons.org/licenses/by/4.0/

\begin{abstract}
It is necessary to evaluate performance using a proper combination of all resources of supply chain in the best possible way to provide products and services in the market. One strategy to measure supply chain efficiency is the data envelopment analysis (DEA), which involves use of current inputs and outputs to evaluate supply chain performance. Therefore, the outcome of each DEA evaluation is not suitable for providing suitable benchmark for the future. Hence, managers are not able to improve the activities of their subset using the results of DEA model. For this purpose, we forecast data of units under evaluation using system dynamics simulation and then we present a proper model to formulate strategies for improving performance using the proposed DEA model. Finally, we implemented the designed algorithm in the milk industry of Fars province (Iran), and proper strategies for improving the efficiency of this industry were developed.
\end{abstract}

\section{Keywords}

Supply Chain Management, Benchmarking, Data Envelopment Analysis, System Dynamics Simulation

\section{Introduction}

In today's global market, companies are not units with unique brands that can operate independently. The complexity of goods and services in today's world is so that an organization can rarely produce or provide a service by itself without 
the help and cooperation of other organizations. The challenges in the business world have led to the emergence of supply chain approach that goes beyond the boundaries among the companies and includes all interactions, ranging from supply of raw materials to delivering finished goods to customers. In the challenging and intensely competitive environment, supply chains must constantly improve their performance to ensure their survival.

This cannot be achieved except by evaluating performance. Proper design and evaluation of supply chain are important issues for managers and researchers, which increases the complexity of the process because of the interrelationships between the units involved. Thus, in designing a performance evaluation system, all communications, interactions, preferences, effects and limitations should be considered as far as possible so that the results of the evaluation of a supply chain offer more accurate feedback to improve the performance.

Demand management, optimal level of product accessibility and reduction of inventory costs (ordering, maintenance and shortages) through the chain are significant goals of the supply chain, which requires the design of a proper performance evaluation system. One of the most challenging fields in this area is the choice of performance indexes and the use of different techniques to evaluate performance. A useful technique used in assessment of the supply chain is data envelopment analysis (DEA). This technique calculates efficiency and evaluates the system performance using a weighted ratio of outputs to inputs and the creation of an efficient frontier. In other words, DEA is one of the techniques which can consider internal complexities of the supply chain in the evaluation process and offer a more accurate and more realistic evaluation.

The DEA has also some limitations like other methods. One of the problems with this technique is that the DEA models use the present and the past inputs and outputs to evaluate. So, consequently, the results obtained on the basis of the past data cannot be a beacon of light to guide the organization towards the future. The managers are not able to plan for the future and to improve the activities of their subsets using the results obtained from DEA. In other words, the classic DEA models cannot offer a proper benchmark for the future. To deal with this problem, numerous methods have been proposed up to now, including the method presented by [1]; it uses goal programming to search for production possibility set and the method presented by reference [2] which uses also a goal programming method in order to locate points on the efficient frontier that are evaluated at the closest conditions to the under evaluation unit. These methods consider the units evaluated as one-stage units and ignore inter-organizational relations.

This weakness of DEA is exactly the strength of the system dynamics simulation. The model of system dynamics simulation is able to forecast data and to describe very complex systems, and can be used to test the systems which are not yet in existence or to test existing systems without changing them.

The food supply chain is one of the types of supply chains which need special attention due to its complexity, importance, and role in people's daily lives and 
health of people. Therefore, selection of the best supplier of the raw materials and improvement of the performance of the food supply chain can be an important step towards achieving macroeconomic objectives of a country on the one hand, and the public health on the other hand. One of the most important activities in the improvement process is the measurement and evaluation, which provides premises for planning for the improvement by identifying the current status of the results and outputs of the food industry. DEA model uses past data so strategic decision is taken based on it will not succeed in real world. This problem, as well as the dynamics in the business environment, highlights the need to use simulation techniques for future-based assessment. Therefore, focusing on future periods, the present study tries to formulate an organizational strategy using a combination of data envelopment analysis and system dynamics simulation to provide a proper model for the improvement of the supply chain performance.

This study utilizes system dynamic, along with DEA, to introduce benchmark of inefficient supply chain. To this end, inputs and outputs of each supplier are forecasted by system dynamics simulation. Then, network DEA model is applied to present a benchmark for inefficient units. Subsequently, based on obtained results, a strategy plan is proposed for improving performance to achieve the best performance of the inefficient units.

In the present work, we review previous research in Section 2, followed by methodology in Section 3. In Section 4, we present a case study which will be followed by concluding remarks in Section 5 .

\section{Review of the Literature}

In recent decades, managers have witnessed global dramatic changes through advances in technology, the globalization of markets and stabilization of the political economy. With the increase in the number of competitors, organizations have been forced to improve inter-organizational processes to stay in the competition scene. In the 1980s, companies searched for techniques and strategies by which they can reduce production costs and compete in different markets. Some of these techniques include the just-in-time production system, Kanban system, lean manufacturing, total quality management, and so on. The companies have been able to reduce their production costs as much as possible by using these techniques, but competitors have also been able to reduce their production costs as much as possible by using the same techniques.

So, to reduce the costs and stay in the competitive market, other potential opportunities to reduce costs should be found. One of the options which involve many potential opportunities to reduce costs is the supply chain [3]. A supply chain includes all stages (chain members) which play either directly or indirectly a role in meeting demands of a customer [4] [5]. Supply Chain Management (SCM) involves integrating key business processes from end users by original suppliers to provide different products and services, as well as information 
which enhance the value for various stakeholders [6].

According to reference [4], the conceptual framework of supply chain consists of three tightly coupled components: supply chain structure (a network of companies), business processes of the supply chain, and its components. Supply chain structure consists of all the companies involved in the production chain, services from raw materials to the end user, and relations among them (by which business activities or business processes are done). According to reference [4], this structure forms a holding company (controlling company) and several related companies (suppliers and customers). The dimensions to be considered involve the length of the supply chain and the number of suppliers and customers in each level. Note that the supply chain does not emerge in the form of a chain, but it is more like the branches of a tree whose roots and branches are the symbols of a network [7]. Business processes are activities that create special output with added value for the customer.

As this issue deals with measuring the performance supply chain members, and integrating and coordinating their performance, however, it is a difficult task. There are two obstacles in measuring the value of chain efficiency. One of them is that there are several efficiency measures determining the performance of each supply chain member, and there is a conflict between the chain members in relation to the specific efficiency [8]. These problems cause that various tools are applied in performance evaluation of supply chain. For example, reference [9] discussed binary Multi-Objective Optimization (MOP) as an attractive method based on Quality Function Deployment (QFD) method to evaluate supply chain of garment industry. Also, a multi-objective optimization and genetic algorithm were applied in multi-national automotive supply chain spread in Europe by [10]. A novel idea was proposed by [11]; they developed a method based on graph theory to evaluate supply chains in Japan.

It is important to note that there are many DEA models in supply chain performance evaluation, as well as supplier selection. Many of them, however, have problems. Research has shown that classic DEA models cannot correctly identify supply chain efficiency and the efficiency of the overall supply chain performance does not necessarily indicate the assessment of the individual components of the supply chain [7]. As a result, progress in achieving the best action may be uneven. In other words, improvement of a member's performance affects the efficiency of other members due to the intermediate measures.

In the DEA literature, there are different methods that have the potential to be used in the evaluation of supply chain efficiency. References [12] [13] proposed two methods to model efficiency in the form of a two-stage process. Reference [14] has created the network DEA for modeling multi-stage processes, in general, involving intermediate inputs and outputs. Reference [15] presented a structure for performance measurement for systems consisting of two subsystems that were together in a series, which provides a simultaneous and separate measurement of the efficiency of the overall system and each subsystem. Reference [16] 
focused on supply chain with bi-level structure including follower and leader; they applied cost efficiency DEA model to evaluate these structures.

Although the two-stage models proposed by references [17] [18] [19] can be extrapolated to the decision-making units (DMUs) with over two stages, unfortunately such a generalization requires that multi-stage processes have a unique common feature where all outputs at each stage are only the inputs in the next stage. In other words, excluding the first stage, any stage will not have independent input (and/or output) that enters or exits the process at that stage. There are more common cases where every stage is an open system, which involves also inputs (and/or outputs) specific to itself, in addition to the intermediate measures. These open multi-stage structures are fairly common, especially in the industry. In many cases, the output of a stage may be the final form which enters into the consumer market, and what remains is processed in the next stage, so that a more specific form of the product is achieved. Petrochemical and perfumery industries are cases in point [7].

Reference [12] has developed a method to improve value chain efficiency by the sensitivity analysis of returns to scale. Reference [20] also showed that the game model can be used to determine a unique complete secondary Nash equilibrium (if available). In this study, it is assumed that the returns to scale are constant, which can be generalized to variable returns to scale. Reference [21] conducted a similar study and represented a two-stage non-cooperative buyer-seller model in which leader initially decides and then considering common processes; he optimizes his decision based on the follower. This model maximizes the cross-sectional efficiency of seller and buyer by assigning weights to common processes and actions calculates realistic efficiency (level of output that is used as an input of the in the next level). Also, reference [22] investigated customer value in a two-stage supply by using three perspectives in game theory.

In another study, reference [23] presented a rough DEA model to evaluate supply chain performance. They used an optimist $\alpha$ and a pessimist $\alpha$ in the process of solving the model to transform the model with rough data into a definite linear programming model. In this model, an efficiency interval is applied for the efficiency of any decision-making unit. Efficiency interval is utilized to rank DMUs and the smallest maximum reduction in efficiency is known as an efficient DMU. Then, this rough DEA model is used to evaluate the efficiency of supply chains.

Reference [24] presented firstly two definitions of a production possibility set of supply chain based on constant return to scale. They offer a DEA model for assessment of overall efficiency. In other words, the model deals with efficiency evaluation by finding out the most efficient production abilities in supply chain and by replacing or improving inefficient subsystems and also by identifying the model (efficient) units. Reference [25] considered the internal structure of the supply chain as a network and presented a model to evaluate it. Reference [26] forecast the future efficiency of a green supplier. To this end, they used dynamic 
data envelopment analysis as well as artificial neural networks to evaluate green suppliers in the past, present, and future periods, simultaneously. Notwithstanding, this technique is not suitable for presenting of benchmark for inefficient units.

Artificial Neural Network (ANN) failed to identify cause and effective relationships between processes of supply chain. This weakness of ANN is exactly the strength of the system dynamics simulation. In another study, reference [27] utilized goal programing and robust DEA for benchmarking and ranking sustainable supplier. The benchmarks depend on goals of each DMU, expectations of decision makers are seen as goals, and goals and deviational variables for all goals may change, and therefore, the results will be different for different values.

Reference [28] determined the benchmarks and prioritized the variables of DMUs in DEA models. This method helped them to improve the capability and flexibility of general DEA models and make intelligent investment on target factors that can improve their firms' productivity. Also in another study, reference [29] proposed an integrated method, DEA and data mining, to measure the efficiency of inefficient terminals.

In order to overcome the regression shortcoming of a single dependent variable, reference [30] estimated the efficiency of DMUs and re-evaluated DEA benchmarks by neural networks. Reference [31] established an effective benchmarking approach in DEA by clustering DMUs into a number of layers based on their efficiency and then introduced a benchmarking method through the sequence of layers.

In another study, reference [32] applied clustering methods to estimate a frontier for input-output and clustering of similar DMUs. Based on efficiency concept in DEA, a stepwise benchmarking method is introduced by [33]. Reference [34] evaluated airports by DEA and identified benchmarks. Reference [35] focused on three criteria, i.e. preference, direction and similarity proposing a method for stepwise benchmark target selection. Reference [36] extended the stepwise benchmarking to identify a minimization-improving performance in order to improve the efficiency of units.

Reference [37] focused on the best practice way for benchmark regulation of electricity distribution and compared DEA, stochastic frontier analysis (SFA) and Stochastic non-smooth envelopment of data (StoNED) in regulating the distribution of electricity. They also, examined the performance of these methods by Monte Carlo simulations. Reference [38] specified benchmarks for inefficient units by using of the "optimal" weights for inputs and outputs. Based on linear combination of the efficient DMUs, they proposed benchmarks for an inefficient DMU.

Reference [39] proposed an integrated method for a benchmarking network consisting of an alternative sequence of benchmark goals. They applied K-means clustering, cross-efficiency DEA and context-dependent DEA methods to minimize the amount of resource improvement pattern inconsistency aimed at 
selecting a benchmark targets for an inefficient DMU.

Through an additive efficiency decomposition method in DEA, reference [40] explored the benchmarks of the Investment Trust Corporations in Taiwan and evaluated the management and investment efficiencies of Taiwanese ITCs. Reference [41] determined a pattern of targets in DEA using the iterative solving algorithm for technology with constant returns to scale. Reference [42] developed their method for variable returns to scale.

In another study, reference [43] applied facet of DEA efficient frontier to specify the best frontier for benchmarking and ranking of DMUs. Reference [44] explored the benchmark corporations in a semiconductor industry. DEA models are utilized to ensure that the benchmark standards are precisely selected.

As can be seen, there has been a great deal of research on benchmarking. The major drawback of these methods are that the proposed benchmarks by these methods are suitable for a special period of the time, e.g., past. Information about future of a system in several periods leads to a better performance of a system. Also, forecasting techniques that used for benchmarking only focused on inputs and outputs and their cause and effect relationships have been ignored.

In this study, we present a model based on a new approach and then explain this method. In this method, if managers are able to estimate inputs and outputs in the future, they can forecast the performance of the units under evaluation using this data. So, we introduced firstly the method of system dynamics simulation to forecast the data of the units under evaluation and then we modify the method of using the classic DEA models to provide a proper model.

This paper suggests a new approach to present a benchmark for inefficient units and thus makes significant contributions. In sum, the contributions are as follows:

- Based on system dynamic, cause and effect relationships between demand management, orders delivery, production flow management and inventory completion or purchase, are identified as the processes of supply chain business.

- Simulation of the supply chain based on the system dynamics identifies key business processes in the supply chain.

- Future efficiency of supply chain is forecasted using system dynamics simulation and network DEA and a new ranking approach is proposed.

- Benchmark of inefficient supply chain is presented.

- Based on the results of our approach, strategies are proposed for improving performance to achieve the best performance of the inefficient unit.

\section{Research Methodology}

In this section, using system dynamics simulation technique, we forecast the inputs and outputs and therefore we consider the performance of supply chains that are composed of five members: end customer, retailer, wholesaler, manufacturer, and supplier. Each of the members, with the exception of the end customer and 
supplier which have been assumed to be outside the scope of the model, gets orders from the member immediately before them in the chain and can simultaneously offer the final product (Figure 1). For this purpose, we draw a causal-loop diagram for each level so that it describes the material flow and subordinate information respectively from the previous level to the next level in the supply chain.

To model and simulate supply chain, we should firstly draw the causal loop diagram and then run the simulation, and we translate the causal-loop diagram to the flow chart. The model used in this study involves a supply chain in which the structure is linear and is formed by levels of the end customer, retailer, wholesaler and manufacturer. Each of the interrelated elements proposed by [4] as elements constituting the conceptual framework of the supply chain, has been considered as our conceptual basis in the present study. The elements used to draws the causal-loop diagram of the supply chain in this study are as follows:

A) The demand is defined as the end customer demand and demand from one level to the next immediate level.

B) Orders received in the company (retailer, wholesaler, and manufacturer): Orders consist of the demand sent from the level immediately before the customer level and overdue orders of the same level of the chain. Specially, if the index $i$ is associated with a level of the chain which has been considered, $D_{i-1}$ is the demand of the level immediately before it and $P_{p i}$ is overdue orders of the given level. Then, the orders of the company are as follows:

Orders of $i^{\text {th }}$ company $=D_{i-1}+P_{p i}$

C) Overdue orders (retailer, wholesaler, and manufacturer).

D) On hand inventory (including retailer, wholesaler, and manufacturer): On hand inventory is the amount of the inventory which is available in stock whose value is never negative. On hand inventory is of significant because it shows the customer's specific demand met directly from the inventory in the stock.

E) Demand forecasting (i.e. retailer, wholesaler, and manufacturer): Forecasting is made possible using exponential smoothing.

F) Inventory status (for the retailer, wholesaler, and manufacturer): Inventory status is defined by the following equation:

The inventory status = on hand inventory + orders which have been submitted but not yet received (products when they are ordered) - overdue orders.

$\mathrm{G})$ Inventory completion orders (retailer and wholesaler).

H) Manufacturing orders (related to the manufacturer): Manufacturing and inventory completion orders are given based on the inventory policies adopted in order to manage demand. In addition to the inventory policy, "demand

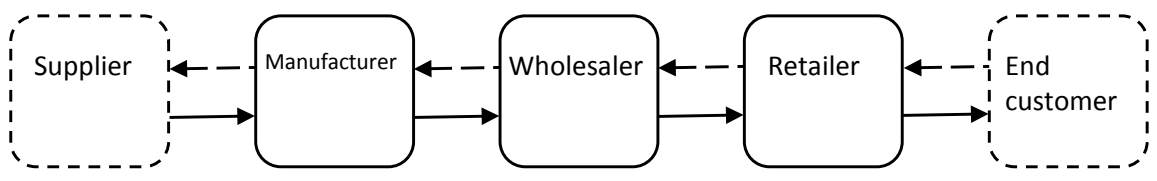

Figure 1. The members of supply chain. 
forecasting", "inventory value" and "lead time of production or supply" are considered to launch manufacturing orders.

I) Lead time (wholesaler and manufacturer).

J) Products on the way (retailer, wholesaler and manufacturer) involves both the inventory which is not available until the lead time (i.e. the time required to prepare and submit product) and the inventory which is available in stock after the completing the production process.

K) Production capacity (the manufacturer): It is shown by the number of product units which are produced in a period of time.

L) Production (the manufacturer).

M) Production lead time (the manufacturer).

N) Fulfillment rates (retailer, wholesaler and manufacturer): Fulfillment rates are the ratio units submitted to the customers in a given period to the total numbers of units demanded by them.

Q) Inventory costs (costs of ordering and maintenance for retailers, wholesalers and manufacturers) and the costs of inventory shortages (when the order fails to be completed on time).

It is logical for these elements to be different according to the type of the modeled supply chain. After identifying the elements which influence supply chain members, we define or draw the relationships or impacts between the elements. Then all the loops made at the time of system modeling, particularly positive loops which make the system unstable, should be considered, and finally, after doing the above steps, we eliminate elements that do not affect the system.

In this study, the end customer is someone who demands final products supplied by the chain (demand pull approach). These customers are people who come to the supermarket to receive the product. The demands created through these customers are estimated by supermarkets as retailers, and the retailers purchase the goods needed to sell from large wholesale warehouses that supply retailers as wholesalers. Several of manufacturing and inventory completion orders display the information flows between all elements forming the chain, whereas the material flows are indicated by delivering goods to these elements. In other words, each member of the chain is engaged to meet the needs of the member immediately before it.

In this study, demand management, orders delivery, production flow management and inventory completion or purchase are considered as the processes of supply chain business, which show management of the demand of each supply chain member. After recognition of all variables in the system, and cause and effect relationships between them, we draw them graphically in the form a cause and effect diagram.

Causal loop diagrams are drawn with regard to the lowest level of the supply chain (Figures 2-4).

According to the process approach and network relationships of the supply chain members, it seems necessary to identify key processes and variables affecting the performance to evaluate more accurately the chain and each of its 


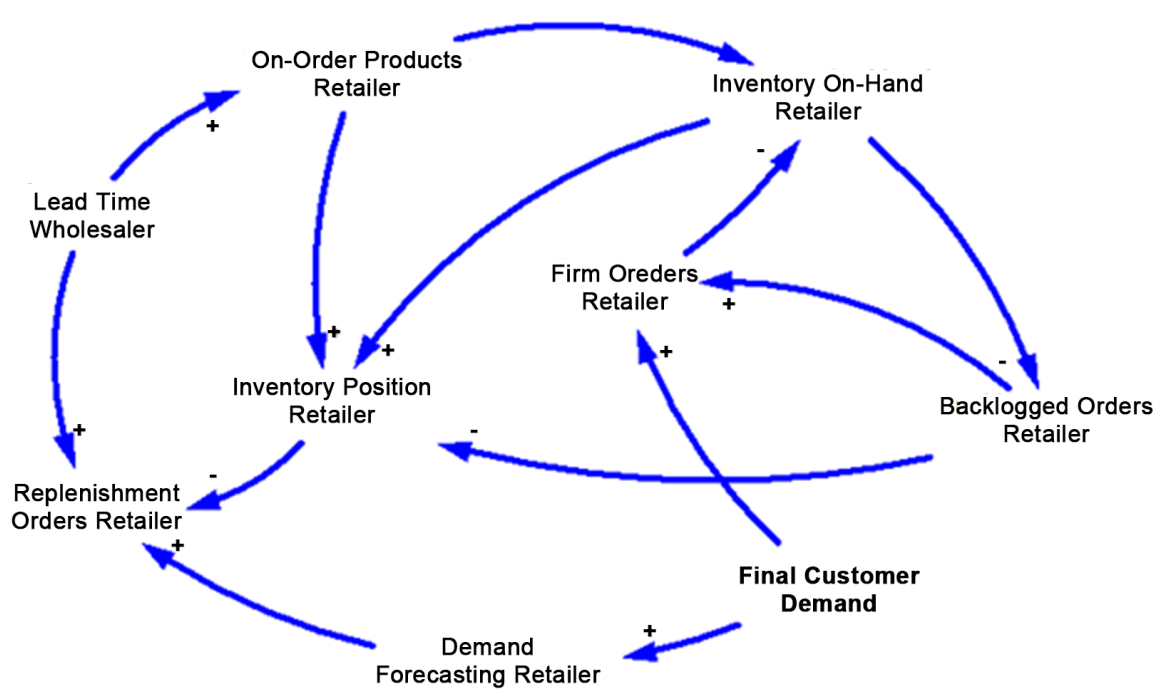

Figure 2. Causal-loop diagram of retailer level [3].

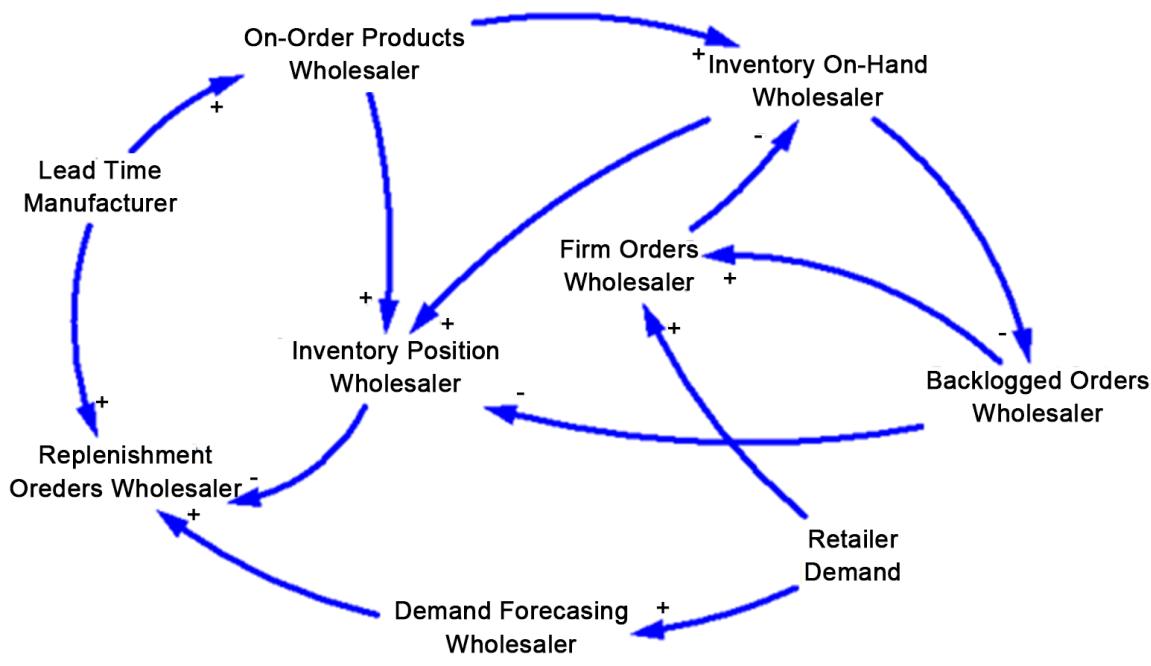

Figure 3. Causal-loop diagram of wholesaler level [3].

members. Simulation of the supply chain based on the system dynamics simulation identifies key business processes in the supply chain. Supply chain management components are those variables through which business processes are integrated and managed through supply chain [10].

The concept of supply chain management requires the total efficiency of the supply chain, as well as the individual efficiency of each member in the supply chain. Each member in the supply chain aims to achieve an efficiency of $100 \%$. $100 \%$ efficiency of a member does not necessarily mean $100 \%$ efficiency of a different member. Due to potential conflicts between members of the supply chain, the inefficiency on the part of a member may be due to the efficiency of another member.

Some measures related to the supply chain members cannot be considered as supply chain "input" or "output". For example, supplier's revenues are not just 


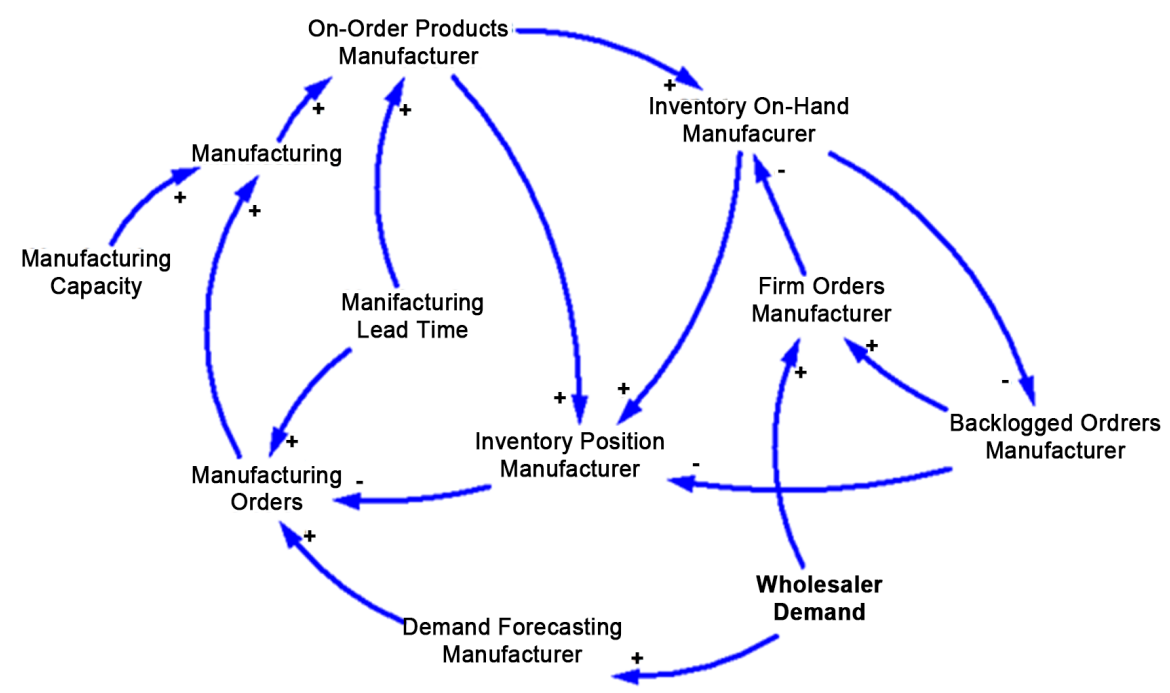

Figure 4. Causal-loop diagram of manufacturer level [3].

the output of the supplier (the supplier aims to increase it), but it is considered as an input for the manufacturer (manufacturer aims to reduce it) as well. For this reason, the concept of supply chain efficiency must be carefully defined and studied, and we need models to define and measure the efficiency of supply chain and its members.

Some methods have been developed to determine the performance of the supply chain members by providing a performance measure [12]. However, there has been no attempt to find the best performance of the supply chain, no reliable mathematical model has been developed to simultaneously. In this study, we focus on 1) define and measure the performance of the overall supply chain with possible conflicts in specific efficiency values, 2) evaluate the performance of the supply chain members, and 3 ) find the best performance and provide solutions to achieve a supply chain with its best performance.

As mentioned, using system dynamics simulation, we identify key business processes of supply chain and indices influencing the processes. After determining key indices of the evaluation of the supply chain performance (Figure 8), we proceed to forecast the values of indices in a future year by simulating the system dynamics. On one hand, DEA models are past and present-oriented, not future-oriented. DEA techniques offer improvement solutions for the inefficient units to achieve the best performance (benchmarking approach). Since the solutions to improve efficiency in inefficient units are provided by benchmarking efficient units, and it is possible that these efficient units have a better performance in the future than their current performance, thus improvement solutions for an inefficient unit lead to efficiency of the unit in the future. Therefore, to overcome this weakness of DEA models, we evaluated the current position of the unit studied which was achieved by system dynamics simulation. Thereby, we turned efficiency improvement solutions into efficiency improvement strategies and provide competitive conditions for the units. 
The proposed DEA model determines the efficiency of the overall supply chain system as well as that of each member of the supply chain and offers solutions to get the best performance from the supply chain. This model eliminates the need for unrealistic assumptions in conventional models of supply chain and the probability models.

Supply chain systems consist of an integrated input-output system where each member of the supply chain applies inputs for production. As a result, we can classify performance measures of the supply chain members as inputs and outputs.

\section{Modeling}

Suppose $I^{\Delta}$ and $R^{\Delta}$ are respectively the symbols of input and output subscript set of the supply chain member $\Delta$. The inputs and outputs of each member the supply chain are shown respectively by $x_{i}^{\Delta}\left(i \in I^{\Delta}\right)$ and $y_{r}^{\Delta}\left(r \in R^{\Delta}\right)$. Now suppose $\boldsymbol{x}_{\Delta}$ and $\boldsymbol{y}_{\Delta}$ are vectors consisting of $x_{i}^{\Delta}\left(i \in I^{\Delta}\right)$ and $y_{r}^{\Delta}\left(r \in R^{\Delta}\right)$. Pareto-Koopmans efficiency is applied to provide a definition of define an efficient supply chain member.

Definition 3-1: Efficient supply chain member [7]: the supply chain member $\Delta$ is efficient if $\left(\boldsymbol{x}_{\Delta}, \boldsymbol{y}_{\Delta}\right)$ is not dominated.

Considering Figure 5, suppose $D I^{\Delta}$ and $D R^{\Delta}$ are direct inputs and outputs of a subscript set for the supply chain member $\Delta$.

Thus the following notation is used to define intermediate inputs and outputs:

$Z_{t}^{S-M}: t^{\text {th }}$ intermediate output from the supplier to the manufacturer, $t=1, \cdots, T$

$Z_{m}^{M-S}: m^{\text {th }}$ intermediate output from the manufacturer to the supplier, $m=1, \cdots, M$

$Z_{f}^{M-W}: f^{\text {h }}$ intermediate output from the manufacturer to the wholesaler, $f=1, \cdots, F$

$Z_{g}^{W-M}: g^{\text {th }}$ intermediate output from the wholesaler to the manufacturer, $g=1, \cdots, G$

$Z_{l}^{M-R}: I^{\text {th }}$ intermediate output from the manufacturer to the retailer, $l=1, \cdots, L$

$Z_{q}^{R-M}: q^{\text {th }}$ intermediate output from the retailer to the manufacturer, $q=1, \cdots, Q$

$Z_{e}^{W-R}: e^{\text {th }}$ intermediate output from the wholesaler to the retailer, $e=1, \cdots, E$ $Z_{n}^{R-W}: n^{\text {th }}$ intermediate output from retailer to wholesaler, $n=1, \cdots, N$

Intermediate outputs have only been defined each one simultaneously represents the input related to a supply chain member. For example $Z_{t}^{S-M}$ (supplier output) represents the input for the manufacturer [7].

Assume that we have $J$ observation related to each supply chain member $(j=1, \cdots, J)$, i.e., we have observed input and output values of $x_{i}^{\Delta}\left(i \in I^{\Delta}\right)$ and $y_{r}^{\Delta}\left(r \in R^{\Delta}\right)$ respectively. The efficiency of each supply chain member $\Delta$ is determined by the following input-oriented DEA model with constant returns to scale [46]: 


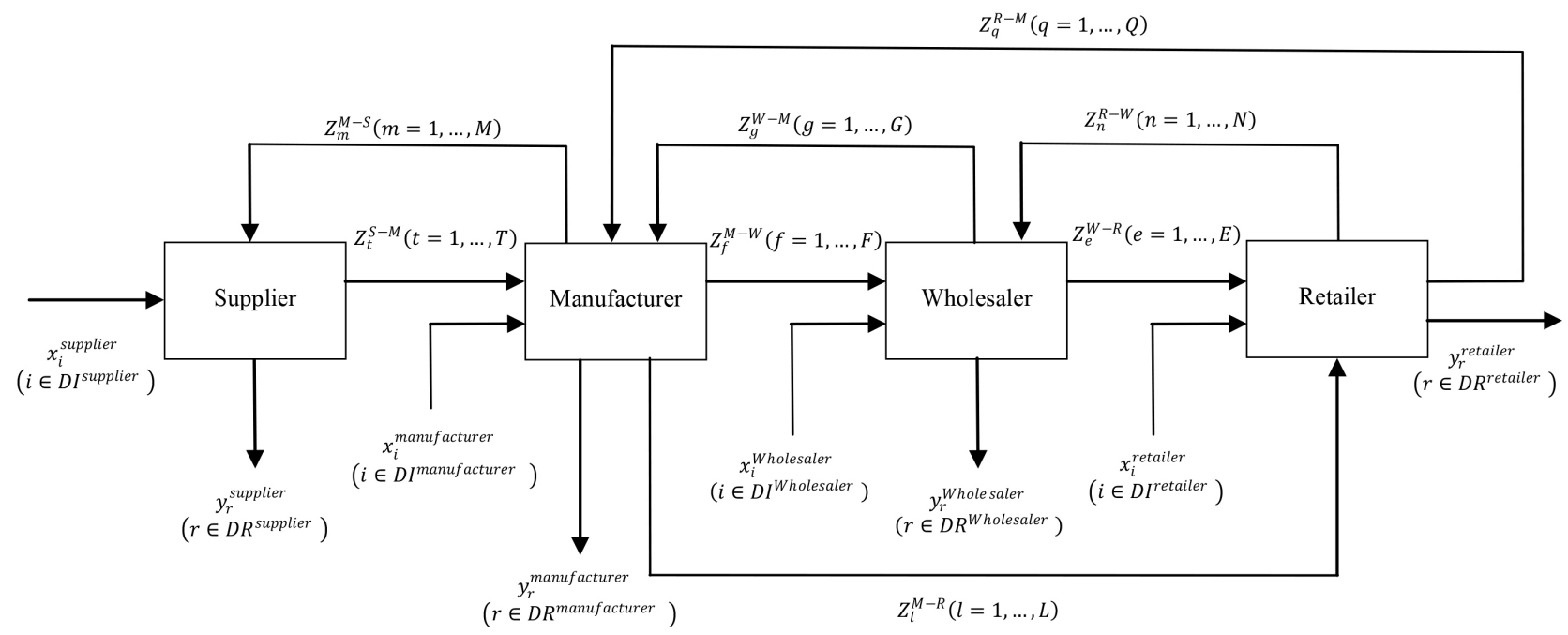

Figure 5. Supply chain.

$$
\begin{array}{ll}
\theta^{\Delta^{*}}= & \min _{\varnothing_{j}^{\Delta}, \theta^{\Delta}} \theta^{\Delta} \\
\text { s.t } & \sum_{j=1}^{J} \varnothing_{j}^{\Delta} x_{i j}^{\Delta} \leq \theta^{\Delta} x_{i j_{0}}^{\Delta}, i \in I^{\Delta} \\
& \sum_{j=1}^{J} \varnothing_{j}^{\Delta} y_{r j}^{\Delta} \leq y_{r j_{0}}^{\Delta}, r \in R^{\Delta} \\
& \varnothing_{j}^{\Delta} \geq 0, j=1, \cdots, J .
\end{array}
$$

If $\theta^{\Delta^{*}}=1$, the supply chain member $\Delta$ is poorly efficient. Also, for the inefficient performance, model (1) provides projection paths onto efficient frontier via the optimum values of $\sum_{j=1}^{J} \varnothing_{j}^{\Delta^{*}} x_{i j}^{\Delta}$ and $\sum_{j=1}^{J} \varnothing_{j}^{\Delta^{*}} y_{r j}^{\Delta}$.

Owing the potential conflicts in the intermediate measures taken by supply chain members, performance of supply chain cannot be simply defined by non-dominancy using model (1). Suppose Assume that $w_{i}$ represents user-specified weights reflecting the priority of the performance (operation) of supply chain members. Thus, the following linear programming problem is applied to assess the performance of a supply chain [7]:

$$
\Omega^{*}=\min _{\Omega_{i}, \lambda_{j}, \beta_{j}, \delta_{j}, \gamma_{j}, \tilde{z}} \sum_{i=1}^{4} w_{i} \Omega_{i} / \sum_{i=1}^{4} w_{i}
$$

s.t:

(Supplier)

$$
\begin{gathered}
\sum_{j=1}^{J} \lambda_{j} x_{i j}^{\text {supplier }}+s_{i}^{- \text {supplier }}=\Omega_{1} x_{i j_{0}}^{\text {supplier }}, i \in D I^{\text {supplier }} \\
\sum_{j=1}^{J} \lambda_{j} y_{r j}^{\text {supplier }}-s_{r}^{+ \text {supplier }}=y_{r j_{0}}^{\text {supplier }}, r \in D R^{\text {supplier }} \\
\sum_{j=1}^{J} \lambda_{j} z_{t j}^{S-M}-s_{1}^{S-M}=\tilde{z}_{t j_{0}}^{S-M}, t=1, \cdots, T \\
\sum_{j=1}^{J} \lambda_{j} z_{m j}^{M-S}+s_{1}^{M-S}=\tilde{z}_{m j_{0}}^{M-S}, m=1, \cdots, M
\end{gathered}
$$




$$
\lambda_{j} \geq 0, j=1, \cdots, J
$$

(Manufacturer)

$$
\begin{aligned}
\sum_{j=1}^{J} \beta_{j} x_{i j}^{\text {manufacturer }}+s_{i}^{- \text {manufacturer }} & =\Omega_{2} x_{i j_{0}}^{\text {manufacturer }}, i \in D I^{\text {manufacturer }} \\
\sum_{j=1}^{J} \beta_{j} y_{r j}^{\text {manufacturer }}-s_{r}^{+ \text {manufacturer }} & =y_{r_{j}}^{\text {manufacturer }}, r \in D R^{\text {manufacturer }} \\
\sum_{j=1}^{J} \beta_{j} z_{t j}^{S-M}+s_{2}^{S-M} & =\tilde{z}_{t_{j}}^{S-M}, t=1, \cdots, T \\
\sum_{j=1}^{J} \beta_{j} z_{m j}^{M-S}-s_{2}^{M-S} & =\tilde{z}_{m j_{0}}^{M-S}, m=1, \cdots, M \\
\sum_{j=1}^{J} \beta_{j} z_{j j}^{M-W}-s_{2}^{M-W} & =\tilde{z}_{f_{j}}^{M-W}, f=1, \cdots, F \\
\sum_{j=1}^{J} \beta_{j} z_{g j}^{W-M}+s_{2}^{W-M} & =\tilde{z}_{g j_{0}}^{W-M}, g=1, \cdots, G \\
\sum_{j=1}^{J} \beta_{j} z_{l j}^{M-R}-s_{2}^{M-R} & =\tilde{z}_{l_{j}}^{M-R}, l=1, \cdots, L \\
\sum_{j=1}^{J} \beta_{j} z_{q j}^{R-M}+s_{2}^{R-M} & =\tilde{z}_{q j_{0}}^{R-M}, q=1, \cdots, Q \\
\beta_{j} \geq 0, j & =1, \cdots, J
\end{aligned}
$$

(Wholesaler)

$$
\begin{aligned}
\sum_{j=1}^{J} \delta_{j} x_{i j}^{\text {wholesaler }}+s_{i}^{- \text {wholesaler }} & =\Omega_{3} x_{i j_{0}}^{\text {wholesaler }}, i \in D I^{\text {wholesaler }} \\
\sum_{j=1}^{J} \delta_{j} y_{r j}^{\text {wholesaler }}-s_{r}^{+ \text {wholesaler }} & =y_{r_{j}}^{\text {wholesaler }}, r \in D R^{\text {wholesaler }} \\
\sum_{j=1}^{J} \delta_{j} z_{f j}^{M-W}+s_{3}^{M-W} & =\tilde{z}_{f_{j_{0}}}^{M-W}, f=1, \cdots, F \\
\sum_{j=1}^{J} \delta_{j} z_{g j}^{W-M}-s_{3}^{W-M} & =\tilde{z}_{g j_{0}}^{W-M}, g=1, \cdots, G \\
\sum_{j=1}^{J} \delta_{j} z_{e j}^{W-R}-s_{3}^{W-R} & =\tilde{z}_{e_{j}}^{W-R}, e=1, \cdots, E \\
\sum_{j=1}^{J} \delta_{j} z_{n j}^{R-W}+s_{3}^{R-W} & =\tilde{z}_{n j_{0}}^{R-w}, n=1, \cdots, N \\
\delta_{j} \geq 0, j & =1, \cdots, J
\end{aligned}
$$

(Retailer)

$$
\begin{aligned}
& \sum_{j=1}^{J} \gamma_{j} x_{i j}^{\text {retailer }}+s_{i}^{- \text {retailer }}=\Omega_{4} x_{i j_{0}}^{r^{\text {retailer }},}, i \in D I^{\text {retailer }} \\
& \sum_{j=1}^{J} \gamma_{j} y_{r j}^{\text {retailer }}-s_{r}^{+ \text {retailer }}=y_{r j_{0}}^{\text {retailer }}, r \in D R^{\text {retailer }}
\end{aligned}
$$




$$
\begin{aligned}
& \sum_{j=1}^{J} \gamma_{j} z_{l j}^{M-R}+s_{4}^{M-R}=\tilde{z}_{l j_{0}}^{M-R}, l=1, \cdots, L \\
& \sum_{j=1}^{J} \gamma_{j} z_{q j}^{R-M}-s_{4}^{R-M}=\tilde{z}_{q j_{0}}^{R-M}, q=1, \cdots, Q \\
& \sum_{j=1}^{J} \gamma_{j} z_{e j}^{W-R}+s_{4}^{W-R}=\tilde{z}_{e j_{0}}^{W-R}, e=1, \cdots, E \\
& \sum_{j=1}^{J} \gamma_{j} z_{n j}^{R-W}-s_{4}^{R-W}=\tilde{z}_{n j_{0}}^{R-w}, n=1, \cdots, N \\
& \gamma_{j} \geq 0, j=1, \cdots, J
\end{aligned}
$$

Obviously, if $\Omega^{*}=1$, then $\theta^{\Delta^{*}}=1$, and $\theta^{\Delta^{*}}$ is the optimal value of the model (2). In other words, if $\Omega^{*}=1$, then all members of the supply chain are efficient.

It should be noted that $\Omega^{*}$ can be an index for input or cost savings for (inefficient) supply chain. The smaller the $\Omega^{*}$, the more savings can be made to achieve the best performance. The same observation can also be made to $\theta^{\Delta^{*}}$ supply chain best performance. Also

$$
\left(w_{1} \theta^{\text {supplier }^{*}}+w_{2} \theta^{\text {manufacturer }}{ }^{*}+w_{3} \theta^{\text {wholesaler }^{*}}+w_{4} \theta^{\text {retailer }}{ }^{*}\right) / \sum_{i=1}^{4} w_{i}
$$

is the index for input savings that can be by all supply members combined. The theorem shows that the overall supply chain can achieve further input savings resulting in better performance.

Theorem 3-1 [7]

$$
\Omega^{*} \leq\left(w_{1} \theta^{\text {supplier }^{*}}+w_{2} \theta^{\text {manufacture }^{*}}+w_{3} \theta^{\text {wholesaler }}{ }^{*}+w_{4} \theta^{\text {retailer }}{ }^{*}\right) / \sum_{i=1}^{4} w_{i}
$$

Based on Zhu's idea, we proposed a model to evaluate overall performance of supply chain and each member as follows:

$$
\begin{aligned}
& \min \left(w^{\text {supplier }}\left(1-\frac{1}{\left|D I^{\text {supplier }}\right|} \sum_{i \in D I^{\text {supplier }}} \frac{s_{i}^{\text {supplier }}}{x_{i o}^{\text {supplier }}}\right)\right. \\
& +w^{\text {manufacturer }}\left(1-\frac{1}{\mid D I^{\text {manufacturer } \mid}} \sum_{i \in D I^{\text {manufacturer }}} \frac{s_{i}^{\text {manufacturer }}}{x_{i o}^{\text {manufacturer }}}\right) \\
& +w^{\text {wholesaler }}\left(1-\frac{1}{\left|D I^{\text {wholesaler }}\right|} \sum_{i \in D I^{\text {wholesaler }}} \frac{s_{i}^{\text {wholesaler }}}{x_{i o}^{\text {wholesaler }}}\right) \\
& \left.+w^{\text {retailer }}\left(1-\frac{1}{\mid D I^{\text {retailer } \mid}} \sum_{i \in D I^{\text {retailer }}} \frac{s_{i}^{\text {retailer }}}{x_{i o}^{\text {retailer }}}\right)\right)
\end{aligned}
$$

s.t.

(Supplier)

$$
\sum_{j=1}^{J} \lambda_{j} x_{i j}^{\text {supplier }}+s_{i}^{- \text {supplier }}=x_{i o}^{\text {supplier }}, i \in D I^{\text {supplier }}
$$




$$
\begin{gathered}
\sum_{j=1}^{J} \lambda_{j} y_{r j}^{\text {supplier }}-s_{r}^{+s u p p l i e r}=y_{r o}^{\text {supplier }}, r \in D R^{\text {supplier }} \\
\sum_{j=1}^{J} \lambda_{j} z_{t j}^{S-M}-s_{1 t}^{S-M}=\tilde{z}_{t o}^{S-M}, t=1, \cdots, T \\
\sum_{j=1}^{J} \lambda_{j} z_{m j}^{M-S}+s_{1 m}^{M-S}=\tilde{z}_{m o}^{M-S}, m=1, \cdots, M \\
\lambda_{j} \geq 0, j=1, \cdots, J
\end{gathered}
$$

(Manufacturer)

$$
\begin{gathered}
\sum_{j=1}^{J} \beta_{j} x_{i j}^{\text {manufacturer }}+s_{i}^{- \text {manufacturer }}=x_{i o}^{\text {manufacturer }}, i \in D I^{\text {manuffacturer }} \\
\sum_{j=1}^{J} \beta_{j} y_{r j}^{\text {manufacturer }}-s_{r}^{+ \text {manufacturer }}=y_{r o}^{\text {manufacturer }}, r \in D R^{\text {manufacturer }} \\
\sum_{j=1}^{J} \beta_{j} z_{t j}^{S-M}+s_{2 t}^{S-M}=\tilde{z}_{t o}^{S-M}, t=1, \cdots, T \\
\sum_{j=1}^{J} \beta_{j} z_{m j}^{M-S}-s_{2 m}^{M-S}=\tilde{z}_{m o}^{M-S}, m=1, \cdots, M \\
\sum_{j=1}^{J} \beta_{j} z_{j j}^{M-W}-s_{2 f}^{M-W}=\tilde{z}_{f o}^{M-W}, f=1, \cdots, F \\
\sum_{j=1}^{J} \beta_{j} z_{g j}^{W-M}+s_{2 g}^{W-M}=\tilde{z}_{g o}^{W-M}, g=1, \cdots, G \\
\sum_{j=1}^{J} \beta_{j} z_{l j}^{M-R}-S_{2 l}^{M-R}=\tilde{z}_{l o}^{M-R}, l=1, \cdots, L \\
\sum_{j=1}^{J} \beta_{j} z_{q j}^{R-M}+s_{2 q}^{R-M}=\tilde{z}_{q o}^{R-M}, q=1, \cdots, Q \\
\beta_{j} \geq 0, j=1, \cdots, J
\end{gathered}
$$

(Wholesaler)

$$
\begin{gathered}
\sum_{j=1}^{J} \delta_{j} x_{i j}^{\text {wholesaler }}+s_{i}^{- \text {wholesaler }}=x_{i o}^{\text {wholesaler }}, i \in D I^{\text {wholesaler }} \\
\sum_{j=1}^{J} \delta_{j} y_{r j}^{\text {wholesaler }}-s_{r}^{+ \text {wholesaler }}=y_{r o}^{\text {wholesaler }}, r \in D R^{\text {wholesaler }} \\
\sum_{j=1}^{J} \delta_{j} z_{f j}^{M-W}+s_{3 f}^{M-W}=\tilde{z}_{f o}^{M-W}, f=1, \cdots, F \\
\sum_{j=1}^{J} \delta_{j} z_{g j}^{W-M}-s_{3 g}^{W-M}=\tilde{z}_{g o}^{W-M}, g=1, \cdots, G \\
\sum_{j=1}^{J} \delta_{j} z_{e j}^{W-R}-s_{3 e}^{W-R}=\tilde{z}_{e o}^{W-R}, e=1, \cdots, E \\
\sum_{j=1}^{J} \delta_{j} z_{n j}^{R-W}+s_{3 n}^{R-W}=\tilde{z}_{n o}^{R-w}, n=1, \cdots, N
\end{gathered}
$$




$$
\delta_{j} \geq 0, j=1, \cdots, J
$$

(Retailer)

$$
\begin{gathered}
\sum_{j=1}^{J} \gamma_{j} x_{i j}^{\text {retailer }}+s_{i}^{\text {-retailer }}=x_{i o}^{\text {retailer }}, i \in D I^{\text {retailer }} \\
\sum_{j=1}^{J} \gamma_{j} y_{r j}^{\text {retailer }}-s_{r}^{+ \text {retailer }}=y_{r o}^{\text {retailer }}, r \in D R^{\text {retailer }} \\
\sum_{j=1}^{J} \gamma_{j} z_{l j}^{M-R}+s_{4 l}^{M-R}=\tilde{z}_{l o}^{M-R}, l=1, \cdots, L \\
\sum_{j=1}^{J} \gamma_{j} z_{q j}^{R-M}-s_{4 q}^{R-M}=\tilde{z}_{q o}^{R-M}, q=1, \cdots, Q \\
\sum_{j=1}^{J} \gamma_{j} z_{e j}^{W-R}+s_{4 e}^{W-R}=\tilde{z}_{e o}^{W-R}, e=1, \cdots, E \\
\sum_{j=1}^{J} \gamma_{j} z_{n j}^{R-W}-s_{4 n}^{R-W}=\tilde{z}_{n o}^{R-w}, n=1, \cdots, N \\
\gamma_{j} \geq 0, j=1, \cdots, J
\end{gathered}
$$

Theorem 3-2 if $\Omega^{*}$ and $\tilde{\Omega}$ are optima of objective function for model (2) and model (3), respectively then $\tilde{\Omega} \leq \Omega^{*}$.

Proof: Suppose that

$$
\begin{aligned}
& \left(\lambda^{*}, \beta^{*}, \delta^{*}, \gamma^{*}, \Omega_{1}^{*}, \Omega_{2}^{*}, \Omega_{3}^{*}, \Omega_{4}^{*}, s^{- \text {supplier }}, s^{+ \text {supplier }}, s^{\text {-manufacturer }} s^{+ \text {manufacturer }},\right. \\
& s^{- \text {wholesaler }}, s^{+ \text {wholesaler }}, s^{- \text {retailer }}, s^{+ \text {retailer }}, s_{1}^{*} S-M, s_{1}^{* M-S}, s_{2}^{* S-M}, s_{m}^{* M-S}, s_{2}^{* M-W}, \\
& \left.s_{2}^{* W-M}, s_{2}^{* M-R}, s_{2}^{* R-M}, s_{3}^{* M-W}, s_{3}^{* W-M}, s_{3}^{* W-R}, s_{3}^{* R-W}, s_{4}^{* M-R}, s_{4}^{* R-M}, s_{4}^{* W-R}, s_{4}^{{ }^{*} R-W}\right)
\end{aligned}
$$

is optimal solution of model (2) and also $\Omega^{*}$ is optima of objective function for the mode. It is easily to see that:

$$
\begin{gathered}
\tilde{\lambda}=\lambda^{*}, \quad \tilde{\beta}=\beta^{*}, \bar{\delta}=\delta^{*}, \bar{\gamma}=\gamma^{*} \\
\tilde{s}^{- \text {supplier }}=s^{- \text {supplier }}+\left(1-\Omega_{1}^{*}\right) x_{o}^{\text {supplier }}, \\
\tilde{s}^{+ \text {supplier }}=s^{+ \text {supplier }} \\
\tilde{s}^{- \text {manufacturer }}=s^{- \text {manufacturer }}+\left(1-\Omega_{2}^{*}\right) x_{o}^{\text {manuffacturer }}, \\
\tilde{s}^{+ \text {manuffacturer }}=s^{+ \text {manuffacturer }} \\
\tilde{s}^{- \text {wholesaler }}=s^{- \text {wholesaler }}+\left(1-\Omega_{3}^{*}\right) x_{o}^{\text {wholesaler }} \\
\tilde{s}^{+ \text {wholesaler }}=s^{+ \text {wholesaler }} \\
\tilde{s}^{- \text {retailer }}=s^{- \text {retailer }}+\left(1-\Omega_{4}^{*}\right) x_{o}^{\text {retailer }} \\
\tilde{s}^{+ \text {retailer }}=s^{+ \text {retailer }} \\
\tilde{s}_{1}^{S-M}=s_{1}^{* S-M}, \quad \tilde{s}_{1}^{M-S}=s_{1}^{* M-S} \\
\tilde{s}_{2}^{M-S}=s_{2}^{* M-S}, \quad \tilde{s}_{2}^{M-W}=s_{2}^{* M-W}, \quad \tilde{s}_{2}^{W-M}=s_{2}^{* W-M}, \\
\tilde{s}_{2}^{M-R}=\tilde{s}_{2}^{* M-R}, \quad \tilde{s}_{2}^{R-M}=s_{2}^{* R-M}
\end{gathered}
$$




$$
\begin{aligned}
& \tilde{s}_{3}^{M-W}=s_{3}^{* M-W}, \quad \tilde{s}_{3}^{W-M}=s_{3}^{* W-M}, \quad \tilde{s}_{3}^{W-R}=s_{3}^{* W-R}, \quad \tilde{s}_{3}^{R-W}=s_{3}^{* R-W} \\
& \tilde{s}_{4}^{M-R}=s_{4}^{* M-R}, \quad \tilde{s}_{4}^{R-M}=s_{4}^{* R-M}, \quad \tilde{s}_{4}^{W-R}=s_{4}^{* W-R}, \quad \tilde{s}_{4}^{R-W}=s_{4}^{* R-W}
\end{aligned}
$$

is feasible solution of model (3) and also:

$$
\begin{aligned}
& \bar{\Omega}=w^{\text {supplier }}\left(1-\frac{1}{\left|D I^{\text {supplier }}\right|} \sum_{i \in D I^{\text {supplier }}} \frac{s^{- \text {supplier }}+\left(1-\Omega_{1}^{*}\right) x_{o}^{\text {supplier }}}{x_{i o}^{\text {supplier }}}\right) \\
& +w^{\text {manufacturer }}\left(1-\frac{1}{\left|D I^{\text {manufacturer }}\right|} \sum_{i \in D I^{\text {manufacturer }}} \frac{s_{i}^{\text {-manufacturer }}+\left(1-\Omega_{2}^{*}\right) x_{o}^{\text {manufacturer }}}{x_{i o}^{\text {manfacturer }}}\right) \\
& +w^{\text {wholesaler }}\left(1-\frac{1}{\left|D I^{\text {wholesaler }}\right|} \sum_{i \in D I^{\text {wholesaler }}} \frac{s_{i}^{\text {-wholesaler }}+\left(1-\Omega_{3}^{*}\right) x_{o}^{\text {wholesaler }}}{x_{i o}^{\text {wholesaler }}}\right) \\
& +w^{\text {retailer }}\left(1-\frac{1}{\left|D I^{\text {retailer }}\right|} \sum_{i \in D I^{\text {retailer }}} \frac{s_{i}^{\text {-retailer }}+\left(1-\Omega_{4}^{*}\right) x_{o}^{\text {retailer }}}{x_{i o}^{\text {retaler }}}\right) \\
& =w^{\text {supplier }} \Omega_{1}^{*}+w^{\text {manufacturer }} \Omega_{2}^{*}+w^{\text {wholesaler }} \Omega_{3}^{*}+w^{\text {retailer }} \Omega_{4}^{*} \\
& +w^{\text {supplier }}\left(-\frac{1}{\left|D I^{\text {supplier }}\right|} \sum_{i \in D I^{\text {supplier }}} \frac{s_{i}^{\text {supplier }}}{x_{i o}^{\text {supplier }}}\right) \\
& +w^{\text {manufacturer }}\left(-\frac{1}{\left|D I^{\text {manufacturer }}\right|} \sum_{i \in D I^{\text {manuffacture }}} \frac{s_{i}^{\text {manufacturer }}}{x_{i o}^{\text {manufacturer }}}\right) \\
& +w^{\text {wholesaler }}\left(-\frac{1}{\left|D I^{\text {wholesaler }}\right|} \sum_{i \in D I^{\text {wholesaler }}} \frac{s_{i}^{\text {wholesaler }}}{x_{i o}^{\text {wholesaler }}}\right) \\
& +w^{\text {retailer }}\left(-\frac{1}{\left|D I^{\text {retailer }}\right|} \sum_{i \in D I^{\text {retailer }}} \frac{s_{i}^{\text {retailer }}}{x_{i o}^{\text {retailer }}}\right) \\
& \leq w^{\text {supplier }} \Omega_{1}^{*}+w^{\text {manufacturer }} \Omega_{2}^{*}+w^{\text {wholesaler }} \Omega_{3}^{*}+w^{\text {retailer }} \Omega_{4}^{*}=\Omega^{*}
\end{aligned}
$$

So $\tilde{\Omega} \leq \bar{\Omega} \leq \Omega^{*}$

So model (3) is more exact for identifying of inefficient supply chains.

As mentioned in the previous section, the information obtained based on the projection presented by DEA models is not enough to improve activities in the future and provide a suitable model. In this method, our work is on this basis that if managers can forecast inputs and outputs in the future, they can present the model of the units under evaluation in the future using this data. For this purpose, system dynamics simulation has been combined with DEA models as follows.

To evaluate the under evaluation supply chain as has been shown at follows, current inputs, intermediate measure and outputs of the chain are considered, but for other units, forecasted inputs, intermediate measures and outputs are used.

$$
\begin{gathered}
D M U_{1}^{k+1}:\left(x_{11}^{k+1}, \cdots, x_{1 m}^{k+1}, z_{11}^{k+1}, \cdots, z_{1 d}^{k+1} y_{11}^{k+1}, \cdots, y_{1 s}^{k+1}\right) \\
D M U_{P}^{K}:\left(x_{p 1}^{k}, \cdots, x_{p m}^{k}, z_{11}^{k}, \cdots, z_{1 d}^{k} y_{p 1}^{k}, \cdots, y_{p s}^{k}\right)
\end{gathered}
$$




$$
D M U_{n}^{K+1}:\left(x_{n 1}^{K+1}, \cdots, x_{n m}^{k+1}, z_{11}^{k+1}, \cdots, z_{1 d}^{k+1} y_{n 1}^{k+1}, \cdots, y_{n s}^{k+1}\right)
$$

So using the results of this evaluation, a new projection can be introduced for inefficient units. In short, the given process is explained as the following algorithm:

1) Collecting the input, intermediate and output values of the units under evaluation.

2) Forecasting the inputs and outputs of the units under evaluation in the future.

3) At each stage, the unit under evaluation is placed in the current coordinates and other units are placed in the forecasted coordinates, and

4) Running the DEA model.

\section{Case Study}

The frontier of supply chain model of the milk industry in Fars province, Iran has two members of retailer and manufacturer. Supplier, and end customer are out of the frontier of the assumed model (Figure 1). Specifications of the model (the values of the parameters used) to simulate each of the supply chains of one year (365 days) has been presented in Table 1.

Each applied research requires the study and recognition of the parameters affecting the subject of the research. Therefore, in order to identify and extract indices affecting supply chain, extensive field studies and library research were done on the variables and indices available in different activity areas of the supply chain. Here the variables are introduced based on APIOBPCS ${ }^{1}$ model [45] [46], which were used to draw the causal loop diagram, see Figure 6 and Figure 7.

Figure 6 and Figure 7 show the end customer demand and the demand of other levels at its next level, orders of the company, overdue orders, inventory status, demand forecasting, inventory completion orders, manufacturing orders, lead times, the products on the way (products produced by the manufacturer and the products which are on their way to the retailer), production capacity, production, production lead time and fulfillment rates.

By identifying which one of the above mentioned variables are auxiliary, level or rate variables, the causal loop diagram must be transformed into a flow chart. Note that the variables required to create an appropriate flow chart are added to the flow chart while they are not required in the causal loop diagram (especially rate variables which are correct level variables).

Given the multiplicity of indices because of the extent of supply chain activities, the most important indices of among the indices presented above, which affect the efficiency evaluation, were selected according to interviews with experts and managers in the industry. Selected indices are in Figure 8.

After identifying the variables as auxiliary, level and rate variables and drawing flow charts, it was needed to write equations related to each of the variables ${ }^{1}$ Automatic Pipeline, Inventory and Order-Based Production Control System (APIOBPCS). 


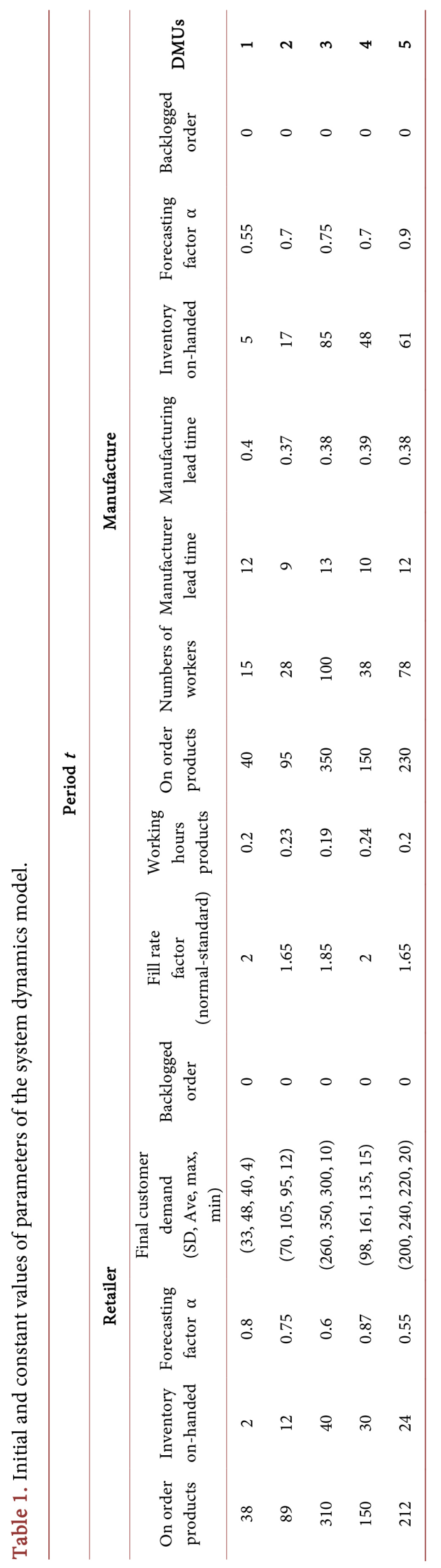




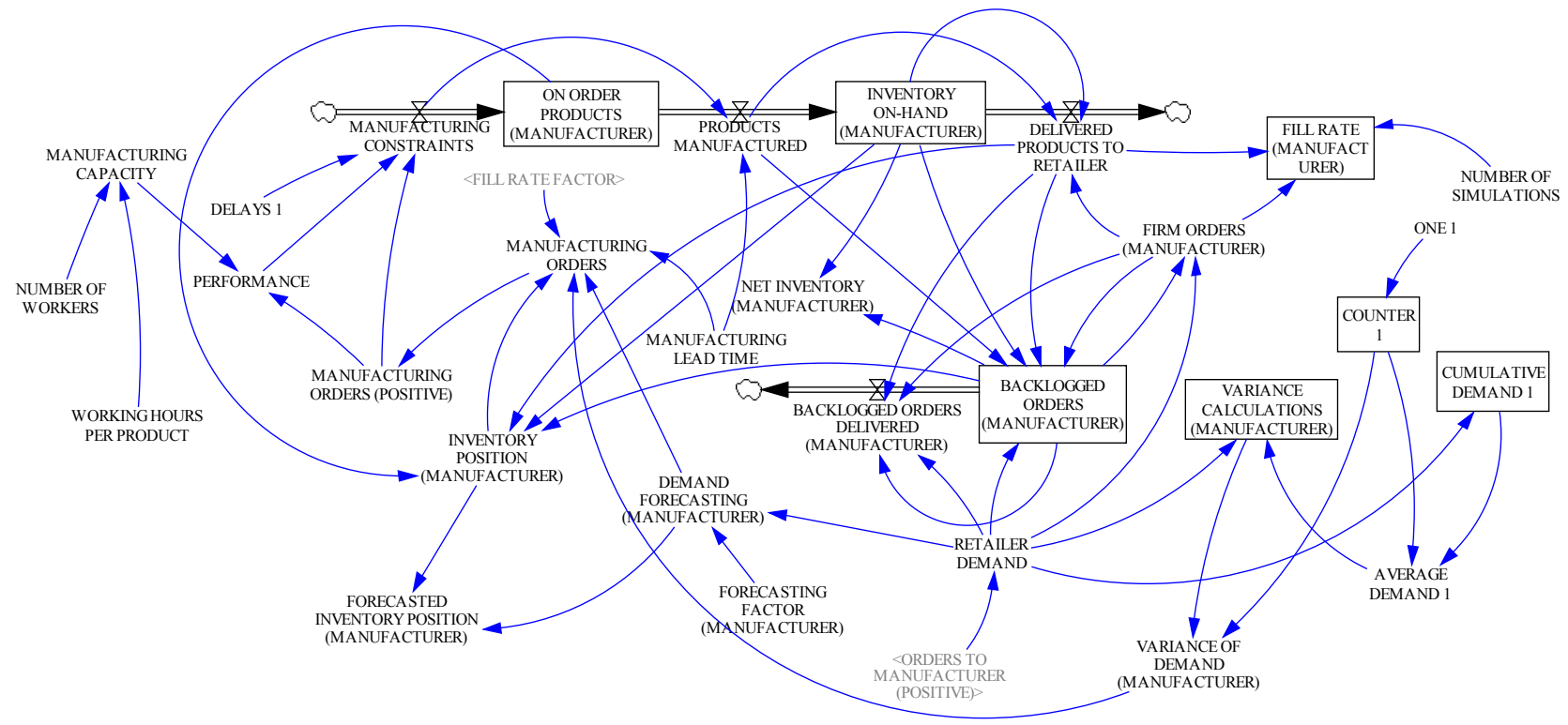

Figure 6. Manufacturer level.

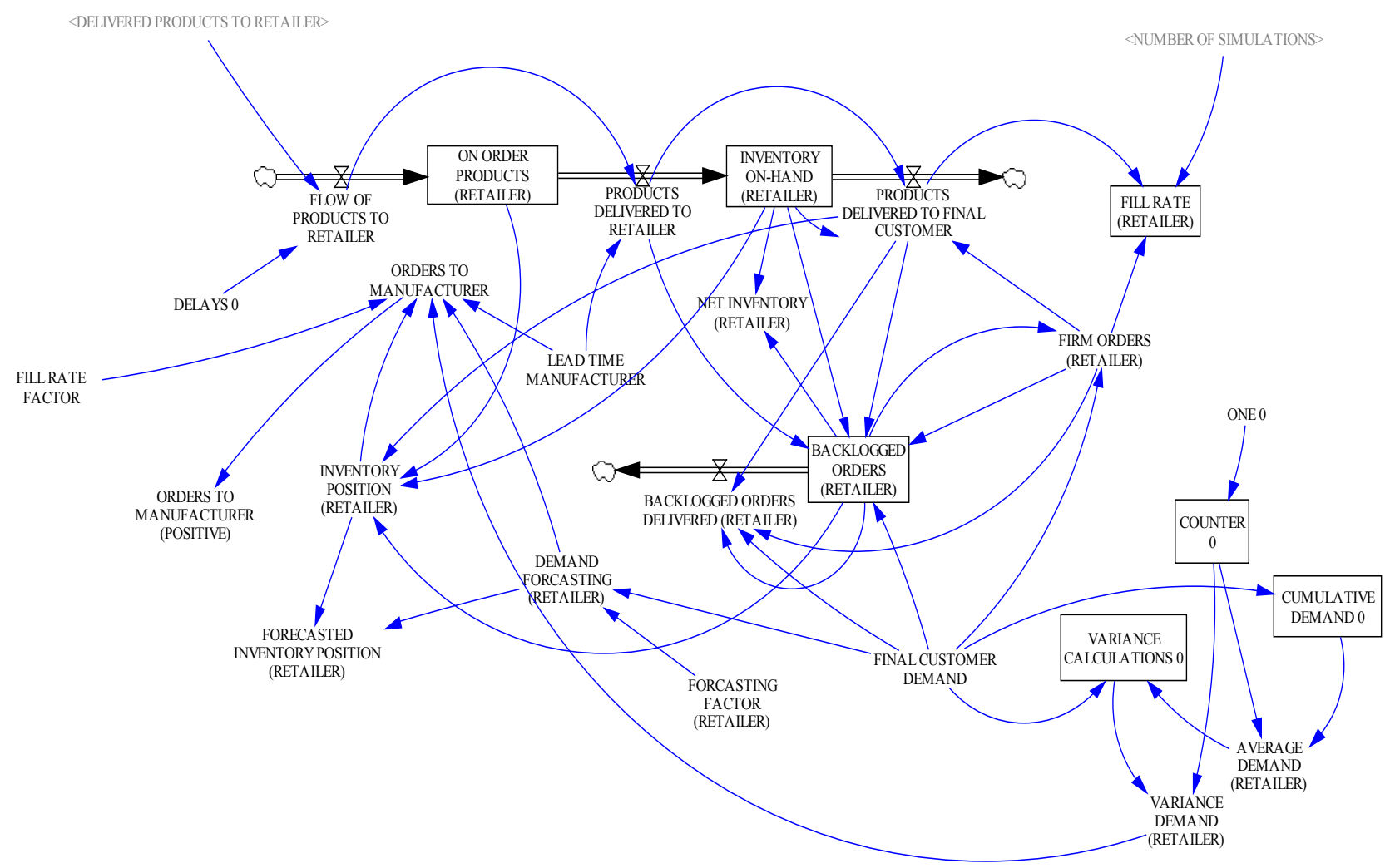

Figure 7. Retailer level

and enter the equations into the software to run the simulation. By entering the equations of each of the supply chain variables, we run the simulation. After determining key indices of performance evaluation as showing in Table 2, the forecasted values of the indices under evaluation in the next year, resulted from the simulation, were recognized in Table 3. 


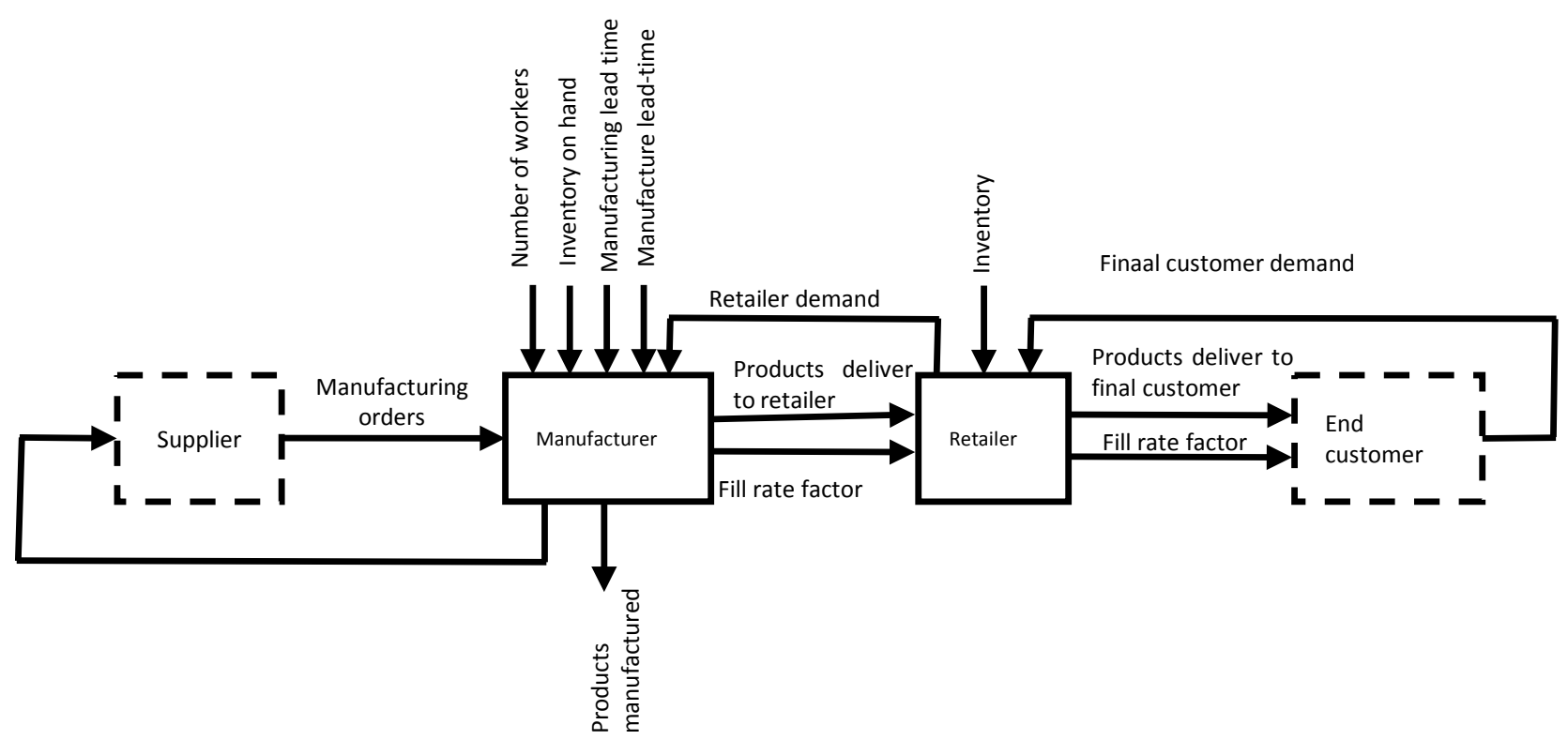

Figure 8. Indices of evaluation of the supply chain performance.

Using the values of indices for each of the chains, DEA model was used based on the proposed method. In order to provide a better understanding and to show more inputs savings for each supply chain member, DEA model (1) was made individually for each member of the chain and efficiency of the overall supply chain was obtained from the average efficiency of its members. We compared the results of both models, which have been presented in Table 4, the results of the model (2) indicate a more accurate performance of the chain and specify, in collaboration with its members, the performance of the overall supply chain.

Columns 2 and 3 in Table 4 specify the performance of supply chains based on model (1). Column 4 shows the efficiency scores of the supply chain members. The supply chain performance has been presented in Column 5 , while $\Omega_{i}^{*}$ has been shown in two columns. Although some supply chain members are efficient, only the performance of one a supply chain (supply chain 4) is efficient. In other words, supply chain 4 the best performance among supply chains.

Note that in this case, all members of the supply chain are efficient. As we can see, the average efficiency score of the supply chain members (Column 4) is greater than that of the supply chain $\left(\Omega^{*}\right)$. For example, consider the supply chain 5 in which a member of the supply chain (retailer) acts efficiently. The average efficiency of the supply chain members is equal to $0 / 952$ and the efficiency score of the supply chain is equal to 0/932, which implies that the supply chain system is able to provide more inputs savings. Optimum values obtained from the model (2) show strategies of moving towards the best performance for inefficient supply chains.

Consider the supply chain $1, \Omega_{2}^{*}=1$ which indicates that the retailer has an efficient performance and that there is no need to change the measures 


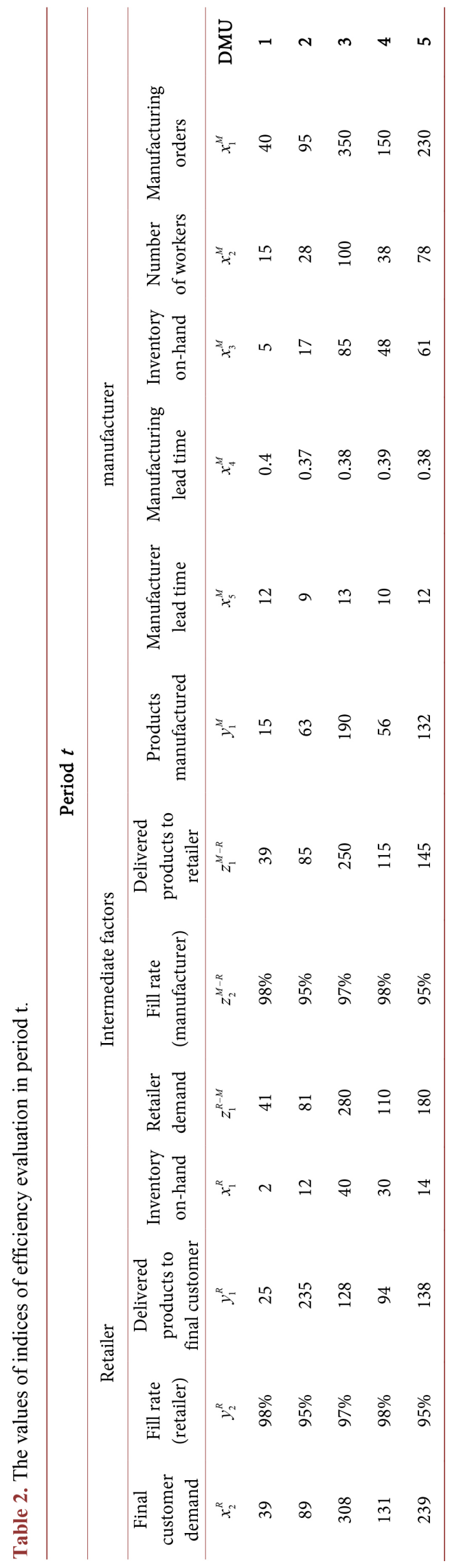




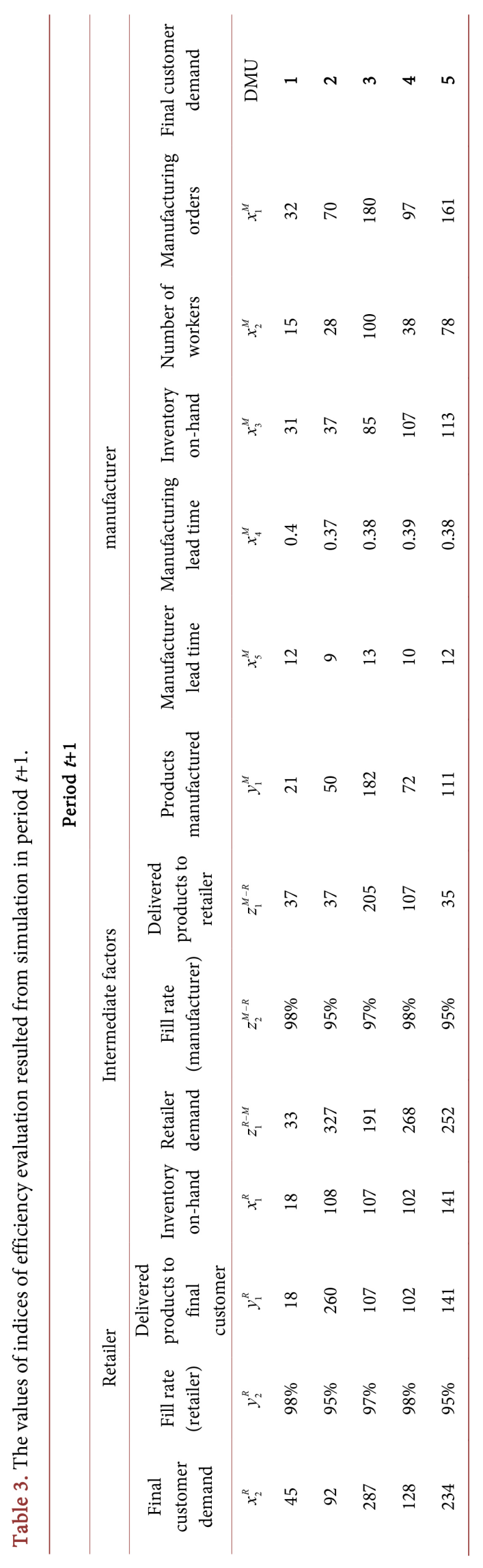


Table 4. The results of the efficiency scores of the supply chain.

\begin{tabular}{ccccccc}
\hline \multicolumn{6}{c}{$\mathrm{DMU}_{\mathrm{o}}$ is placed in the period $t$ and other units are placed in $t+1}$. \\
\hline \multicolumn{5}{c}{ Efficiency of supply chain } & \multicolumn{2}{c}{ Efficiency of member of supply chain } \\
\hline Retailer & manufacturer & Supply chain & Average & Retailer & manufacturer \\
\hline$\Omega_{2}^{*}$ & $\Omega_{1}^{*}$ & $\Omega^{*}$ & & $\theta^{\text {retailer }}$ & $\theta^{\text {manufacturer }}$ & DMU \\
1 & 0.871 & 0.935 & 0.965 & 1 & 0.931 & 1 \\
0.97 & 0.692 & 0.831 & 0.85 & 1 & 0.701 & $\mathbf{2}$ \\
0.747 & 0.948 & 0.847 & 0.986 & 0.972 & 1 & $\mathbf{3}$ \\
1 & 1 & 1 & 1 & 1 & 1 & 4 \\
0.864 & 1 & 0.932 & 0.952 & 1 & 0.904 & $\mathbf{5}$ \\
\hline
\end{tabular}

associated with the retailer, but to achieve the best performance of the supply chain 1, the manufacturer must reduce the inputs of its system to the value of $\Omega_{1}^{*}$. The completion rate of the manufacturer must increase from the current completion rate of $98 \%$ to $99 \%$. Products delivered to the retailer must be reduced by about $1 \%$. These solutions, which are based on the best performance, show that the manufacturer should be able to keep $99 \%$ completion rate, while it reduces the products delivered to the retailer. Some supply chains may work with high cost and product accessibility, while others may tend prefer to have lower levels of service.

Efficiency of DEA presented in this study provides a method to identify and measure supply chain efficiency and also the efficiency of supply chain members making it clear that two supply chains may have different combinations of input-output, but be efficient. Model (2) enables supply chain members to improve collectively supply chain performance. Using model (2), each supply chain can find ways to achieve the best performance and to gain competitive advantage.

\section{Conclusions}

Unlike DEA models, the aim of this study was not to compare and rank the units, because DEA models evaluate the performance based on the past data. Solutions suggested based on the performance of the unit cannot be efficient based on past data and the results cannot be a beacon to guide organizations towards the future.

Therefore, in this study, we decided to give a solution to deal with this problem. We used the system dynamics simulation and by modeling the supply chain behavior and creating relationships between variables of the supply chain. Providing equations which show the relationships between variables, we predicted the behavior of the supply chain in the following year. With the help of the forecasted information on the variables in the future, we evaluated the supply chain performance using DEA. We kept the supply chain under evaluation in its current situation and transfer the remaining supply chains into the future. We 
evaluated the performance of the unit under evaluation in relation to the forecasted performance of the rest of the units in the future. Instead of offering solutions to improve performance based on past data, we presented strategies for improving performance on simulated data to achieve the best performance of the inefficient unit on the frontier of efficiency.

Although the method is effective, there are some limitations for further research. This technique cannot be applied for undesirable inputs or outputs. Uncertainty demand is another problem. So the model needs to extend for stochastic data on pricing decision and product choice. Furthermore, Malmquist index can be considered to evaluate technological changes in two periods of time.

\section{Conflicts of Interest}

The authors declare no conflicts of interest regarding the publication of this paper.

\section{References}

[1] Golony, B. (1988) An Interactive MOLP Procedure for the Extension of DEA to Effectiveness Analysis. Journal of Operational Research Society, 39, 725-734. https://doi.org/10.1057/jors.1988.127

[2] Stewart, T.J. (2010) Goal Directed Benchmarking for Organizational Efficiency. Omega, 38, 534-539. https://doi.org/10.1016/j.omega.2010.01.004

[3] Zeydan, M., Colpan, C. and Cobanoglu, C. (2011) A Combined Methodology for Supplier Selection and Performance Evaluation. Expert Systems with Applications 38, 2741-2751. https://doi.org/10.1016/j.eswa.2010.08.064

[4] Lambert, D.M. and Cooper, M.C. (2000) Issues in Supply Chain Management. Industrial Marketing Management, 29, 65-83. https://doi.org/10.1016/S0019-8501(99)00113-3

[5] Cheung, K.L. and Hansman, W.H. (2000) An Exact Performance Evaluation for the Supplier in a Two-Echelon Inventory System. Operations Research, 48, 646-653. https://doi.org/10.1287/opre.48.4.646.12421

[6] Cooper, M.C., Ellram, L.M., Gardner, J.T., et al. (1997) Meshing Multiple Alliances. Journal of Business Logistics, 18, 67-89.

[7] Zhu, J. (2014) Quantitative Models for Performance Evaluation and Benchmarking: Data Envelopment Analysis with Spreadsheets. 3rd Edition, Springer, Cham, Heidelberg, New York, Dordrecht, London.

[8] Seiford, L.M. and Zhu, J. (1999) Profitability and Marketability of the Top 55 US Commercial Banks. Management Science, 45, 1270-1288. https://doi.org/10.1287/mnsc.45.9.1270

[9] Chowdhury, Md.M.H. and Quaddus, M.A. (2015) Multiple Objective Optimization Based QFD Approach for Efficient Resilient Strategies to Mitigate Supply Chain Vulnerabilities: The Case of Garment Industry of Bangladesh. Omega, 57, 5-21. https://doi.org/10.1016/j.omega.2015.05.016

[10] Avci, M.G. and Selim, H. (2018) A Multi-Objective Simulation-Based Optimization Approach for Inventory Replenishment Problem with Premium Freights in Convergent Supply Chains. Omega, 80, 153-165. https://doi.org/10.1016/j.omega.2017.08.016 
[11] Nakatani, J., Tahara, K., Nakajima, K., et al. (2018) A Graph Theory-Based Methodology for Vulnerability Assessment of Supply Chains Using the Life Cycle Inventory Database. Omega, 75, 165-181. https://doi.org/10.1016/j.omega.2017.03.003

[12] Seiford, L.M. and Zhu, J. (1999) Sensitivity and Stability of the Classification of Returns to Scale in Data Envelopment Analysis. Journal of Productivity Analysis, 12, 55-75. https://doi.org/10.1023/A:1007803207538

[13] Chen, Y. and Zhu, J. (2004) Measuring Information Technology's Indirect Impact on Firm Performance. Information Technology \& Management Journal, 5, 9-22. https://doi.org/10.1023/B:ITEM.0000008075.43543.97

[14] Fare, R. and Grosskopf, S. (2000) Network DEA. Socio-Economic Planning Sciences 34, 35-49. https://doi.org/10.1016/S0038-0121(99)00012-9

[15] Golany, B., Hackman, S.T. and Passy, U. (2006) An Efficiency Measurement Framework for Multistage Production Systems. Annals of Operations Research, 145, 51-68. https://doi.org/10.1007/s10479-006-0025-8

[16] Zhou, X., Luo, R., Tu, Y., et al. (2018) Data Envelopment Analysis for Bi-Level Systems with Multiple Followers. Omega, 77, 180-188.

https://doi.org/10.1016/j.omega.2017.06.007

[17] Kao, C. and Hwang, S.N. (2008) Efficiency Decomposition in Two-Stage Data Envelopment Analysis: An Application to Non-Life Insurance Companies in Taiwan. European Journal of Operational Research, 185, 418-429.

https://doi.org/10.1016/j.ejor.2006.11.041

[18] Liang, L., Yang, F., Cook, W.D., et al. (2006) DEA Models for Supply Chain Efficiency Evaluation. Annals of Operations Research, 145, 35-49.

https://doi.org/10.1007/s10479-006-0026-7

[19] Chen, Y., Cook, W.K., Li, N., et al. (2009) Additive Efficiency Decomposition in Two-Stage DEA. European Journal of Operational Research, 196, 1170-1176. https://doi.org/10.1016/j.ejor.2008.05.011

[20] Chen, Y., Liang, L. and Yang, F. (2006) A DEA Game Model Approach to Supply Chain Efficiency. Annals of Operation Research, 145, 5-13. https://doi.org/10.1007/s10479-006-0022-y

[21] Liang, L., Cook, W.D. and Zhu, J. (2008) DEA Models for Two-Stage Processes: Game Approach and Efficiency Decomposition. Naval Research Logistics, 55, 643-653. https://doi.org/10.1002/nav.20308

[22] Luo, Z., Chen, X. and Kai, M. (2018) The Effect of Customer Value and Power Structure on Retail Supply Chain Product Choice and Pricing Decisions. Omega, 77, 115-126. https://doi.org/10.1016/j.omega.2017.06.003

[23] Xu, J., Li, B. and Wu, D. (2009) Rough Data Envelopment Analysis and Its Application to Supply Chain Performance Evaluation. International Journal of Production Economics, 122, 628-638. https://doi.org/10.1016/j.ijpe.2009.06.026

[24] Yang, F., Wu, D., Liang, L., et al. (2011) Supply Chain DEA: Production Possibility Set and Performance Evaluation Model. Annals of Operations Research, 185, 195-211. https://doi.org/10.1007/s10479-008-0511-2

[25] Chen, C. and Yan, H. (2011) Network DEA Model for Supply Chain Performance Evaluation. European Journal of Operational Research, 213, 147-155. https://doi.org/10.1016/j.ejor.2011.03.010

[26] Shabanpour, H., Yousefi, S. and Saen, R.F. (2017) Forecasting Efficiency of Green Suppliers by Dynamic Data Envelopment Analysis and Artificial Neural Networks. Journal of Cleaner Production, 142, 1098-1107. 
https://doi.org/10.1016/j.jclepro.2016.08.147

[27] Yousefi, S., Shabanpour, H., Fisher, R., et al. (2016) Evaluating and Ranking Sustainable Suppliers by Robust Dynamic Data Envelopment Analysis. Measurement, 83, 72-85. https://doi.org/10.1016/j.measurement.2016.01.032

[28] Sharma, M.J. and Yu, S.J. (2010) Benchmark Optimization and Attribute Identification for Improvement of Container Terminals. European Journal of Operational Research, 201, 568-580. https://doi.org/10.1016/j.ejor.2009.03.021

[29] Sharma, M.J. and Yu, S.J. (2009) Performance Based Stratification and Clustering for Benchmarking of Container Terminals. Expert System with Applications, 36, 5016-5022. https://doi.org/10.1016/j.eswa.2008.06.010

[30] Bose, A. and Patel, G.N. (2015) "Neural DEA"-A Framework Using Neural Network to Re-Evaluate DEA Benchmarks. OPSEARCH, 52, 18-41. https://doi.org/10.1007/s12597-013-0170-1

[31] Lim, S., Bae, H. and Lee, L.H. (2011) A Study on the Selection of Benchmarking Paths in DEA. Expert Systems with Applications, 38, 7665-7673. https://doi.org/10.1016/j.eswa.2010.12.148

[32] Dai, X. and Kuosmanen, T. (2014) Best-Practice Benchmarking Using Clustering Methods: Application to Energy Regulation. Omega, 42, 179-188. https://doi.org/10.1016/j.omega.2013.05.007

[33] Lozano, S. and Calzada-Infante, L. (2017) Computing Gradient-Based Stepwise Benchmarking Paths. Omega, 81, 195-207.

[34] Adler, N., Liebert, V. and Yazhemsky, E. (2013) Benchmarking Airports from a Managerial Perspective. Omega, 41, 442-458. https://doi.org/10.1016/j.omega.2012.02.004

[35] Park, J., Bae, H. and Lim, S. (2012) A DEA-Based Method of Stepwise Benchmark Target Selection with Preference, Direction and Similarity Criteria. International Journal of Innovative Computing, Information and Control, 8, 5821-5834.

[36] Park, J., Lim, S. and Bae, H. (2012) DEA-Based Port Efficiency Improvement and Stepwise Benchmarking Target Selection. Information, 15, 6155-6172.

[37] Kuosmane, T., Saastamoinen, A.S. and Sipiläinen, T. (2013) What Is the Best Practice for Benchmark Regulation of Electricity Distribution? Comparison of DEA, SFA and StoNED Methods. Energy Policy, 61, 740-750. https://doi.org/10.1016/j.enpol.2013.05.091

[38] Patel, G.N. and Bose, A. (2014) Seeking Alternative DEA Benchmarks. OPSEARCH, 51, 23-35. https://doi.org/10.1007/s12597-013-0130-9

[39] Park, J. and Sung, S. (2016) Integrated Approach to Construction of Benchmarking Network in DEA-Based Stepwise Benchmark Target Selection. Sustainability, 8, 600. https://doi.org/10.3390/su8070600

[40] Lu, W.M., Liu, J.S., Kweh, Q.L., et al. (2016) Exploring the Benchmarks of the Taiwanese Investment Trust Corporations: Management and Investment Efficiency Perspectives. European Journal of Operational Research, 248, 607-618. https://doi.org/10.1016/j.ejor.2015.06.065

[41] Lozano, S. and Villa, G. (2005) Determining a Sequence of Targets in DEA. Journal Operational Research Society, 56, 1439-1447. https://doi.org/10.1057/palgrave.jors.2601964

[42] Lozano, S. and Villa, G. (2010) Gradual Technical and Scale Efficiency Improvement in DEA. Annals of Operations Research, 173, 123-136. https://doi.org/10.1007/s10479-009-0583-7 
[43] Ruiz, J.L. and Sirvent, I. (2016) Common Benchmarking and Ranking of Units with DEA. Omega, 65, 1-9. https://doi.org/10.1016/j.omega.2015.11.007

[44] Tsaia, C.H., Wu, H.Y., Chen, I.S, et al. (2017) Exploring Benchmark Corporations in the Semiconductor Industry Based on Efficiency. Journal of High Technology Management Research, 28, 188-207. https://doi.org/10.1016/j.hitech.2017.10.007

[45] Campuzano, F. and Mula, J. (2011) Supply Chain Simulation: A System Dynamics Approach for Improving Performance. Springer, London, Dordrecht, Heidelberg, New York.

[46] John, S., Naim, M.M. and Towill, D.R. (1994) Dynamic Analysis of a WIP Compensated Decision Support System. International Journal of Manufacturing Systems Design, 1, 283-297. 